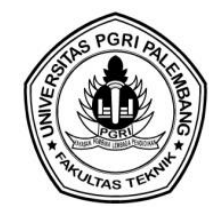

\title{
ANALISA PENGARUH PENAMBAHAN LIMBAH GYPSUM TERHADAP NILAI CBR TANAH DASAR DI RUAS JALAN BK 1 DESA TANJUNG BULAN KABUPATEN OKU TIMUR
}

\author{
Lindawati $^{{ }^{*}}$, Enda Kartika Sari ${ }^{2}$ \\ ${ }^{12}$ Program Studi Teknik Sipil Fakultas Teknik Universitas Baturaja \\ *Corresponding Author, Email: lindaunbara@gmail.com
}

\begin{abstract}
ABSTRAK
Tanah merupakan material yang selalu berhubungan dengan teknologi konstruksi sipil.Karena besarnya pengaruh tanah terhadap perencanaan seluruh konstruksi, maka tanah menjadi komponen yang sangat diperhatikan dalam perencanaan konstruksi. Dari berbagai jenis tanah tanah dasar adalah tanah yang paling banyak ditemukan masalah. Pada kenyataanya tanah dasar bersifat kurang menguntungkan secara teknis untuk mendukung suatu pekerjaan konstruksi. Maka dari itu, diperlukannya perbaikan tanah guna untuk meningkatkan daya dukung tanah, salah satunya adalah dengan stabilisasi perbaikan tanah secara kimiawi. Salah satu parameter yang dapat diketahui apakah tanah tersebut daya dukungnya baik atau tidak. Maka dilakukan pengujian stabilitas tanah dengan menambahkan limbah gypsum yang diolah menjadi serbuk sebagai bahan pencampur tanah. Hasil dari pengujian didapat nilai CBR (California Bearing Ratio) terbesar terjadi pada sampel tanah yang dicampur dengan limbah gypsum sebanyak 5\%,10\%, $15 \%, 20$ $\%$, terjadi kenaikan sebesar 7,26 pada titik 5 dengan kadar limbah gypsum $15 \%$. Kenaikan ini terjadi karena gypsum mengandung kalsium yang mengikat tanah bermateri organik terhadap dasar. Gypsum juga lebih menyerap banyak air sehingga membuat campuran limbah dan sampel tanah akan menjadi semakin keras dan kuat.
\end{abstract}

Kata kunci : Tanah Dasar, Limbah Gypsum. CBR (California Bearing Ratio)

\section{PENDAHULUAN}

Tanah merupakan material yang selalu berhubungan dengan teknologi konstruksi sipil. Karena besarnya pengaruh tanah terhadap perencanaan seluruh konstruksi, maka tanah menjadi komponen yang sangat diperhatikan dalam perencanaan konstruksi (Suryono, S, 1980). Untuk itu, dalam perencanaan suatu konstruksi harus dilakukan penyelidikan terhadap karakteristik dan kekuatan tanah terutama sifat-sifat tanah yang mempengaruhi kekuatan dukungan tanah dalam menahan beban konstruksi yang ada diatasnya. Salah satu usaha melakukan perbaikan tanah dan meningkatkan daya dukung tanah adalah dengan melakukan stabilisasi perbaikan tanah secara kimiawi. Peningkatan kestabilan tanah biasanya digunakan Polyprophylene Polymer (PP) yang harganya cukup mahal.(Sanglerat, G dkk, 1980)

Biaya yang mahal ini mengakibatkan peningkatan dari harga pembangunan. Untuk mengurangi tingginya biaya perbaikan tanah, dalam penelitian ini dilakukan pengujian stabilitas tanah dengan menambahkan limbah gypsum sebagai bahan pencampur tanah. Jalan merupakan sarana media angkutan darat, harus dapat mendukung kelancaran pergerakan tranportasi seperti yang terjadi pada studi kasus di ruas Jalan Bk 1 Desa Tanjung Bulan Kabupaten OKU Timur dimana pada jalan ini tidak memenuhi sarana media angkutan darat terdapat banyak kerusakan jalan dan permukaan jalan yang tidak 
rata atau bergelombang yang diakibatkan kondisi tanah turun sehingga dapat mengganggu kelancaran tranportasi. Sehingga perlu dilakukan pengujian nilai CBR terhadap tanah lempung untuk mengetahui suatu kondisi tanah dasar (subgrade) yang dapat menahan beban kerja serta lapisan perkerasan yang memadai dan tahan lama atau awet.

\section{TINJAUAN PUSTAKA}

Gypsum adalah salah satu contoh mineral dalam kadar kalsium yang mendominasi. Gypsum yang paling umum di temukan adalah jenis hidrat kalsium sulfat hidrat dengan rumus kimia CaSO42(H2O). Gypsum adalah salah satu dari beberapa mineral yang teruapkan. Gypsum termasuk mineral dengan system kristal monokolin 2/m, namum kristal gipsnya termasuk dalam sifat krital orthorombik. Gypsum pada umumnya berwarna putih, kelabu, coklat kuning dan transparan. Hal ini tergantung mineral lain bercampur dengan gypsum (Vemmy, 2013).

Sekarang ini gypsum banyak dipergunakan pada hiasan bangunan, bahan dasar pembuatan semen, pengisi cat, bahan pembuatan pupuk dan berbagai macam keperluan lainnya. Keuntungan penggunaan gypsum dalam pekerjaan teknik sipil yaitu:

a. Gypsum yang dicampur lempung dapat mengurangi retak karena sodium pada tanah terganti oleh kalsium pada gypsum sehinga pengembangannya lebih kecil.

b. Gypsum dapat meningkatkan stabilitas tanah organik karena mengandung kalsium yang mengikat tanah bermateri organic terhadap lempung yang member stabilitas terhadap agregat tanah.

c. Gypsum meningkatkan kecepatan rembesan air, dikarenakan gypsum lebih banyak menyerap air.

CBR adalah perbandingan antara beban penetrasi suatu beban terhadap bahan standar dengan kedalaman dan kecepatan penetrasi yang sama cara umum dan merupakan suatu perbandingan antara beban percobaan (test load) dengan beban standar (standard load) dan dinyatakan dalam persentase. Harga CBR adalah nilai yang menyatakan kualitas tanah dasar dibandingkan dengan bahan standar berupa batu pecah yang mempunyai nilai CBR sebesar 100\% dalam memikul beban (Ibnu, S, 2006).

Berdasarkan cara mendapatkan contoh tanahnya, CBR dapat dibagi menjadi :

a. CBR lapangan (CBR inplace atau field inplace) digunakan untuk memperoleh nilai CBR asli dari lapangan sesuai dengan kondisi tanah pada saat itu. Umum digunakan untuk perencanaan tebal perkerasan yang lapisan tanahnya tidak akan dipadatkan lagi. Pemeriksaan ini dilakukan dalam kondisi kadar air tinnggi (musim penghujan) (Santoso, B, 2011)

b. CBR lapangan rendaman (undisturbed soapked CBR) digunakan untuk mendapatkan besarnya nilai CBR asli lapangan pada keadaan jenuh air dan tanah mengalami pengemangan (swell) yang maksimum. Hal ini sering digunakan untuk menentukan daya dukung tanah di daerah yang lapisan tanah dasarnya tidak akan dipadat lagi, terletak yang badan jalanya sering terendam pada musim penghujan dan kering pada musim kemarau. Sedangkan pemeriksaakan dilakukan musim kemarau. Pemeriksaan dilakukan dengan mengambil contoh tanah dalam tabung (mould) yang di tekan masuk kedalam tanah mencapai kedalaman yang diinginkan. 
c. CBR Laboratorium. Tanah dasar (subgrade) pada kontruksi jalan baru dapat berupa tanah asli, tanah timbunan atau tanah galian yang telah dipadatkan sampai mencapai kepadatan (95\%) kepadatan maksimum. Dengan demikian daya dukung tanah dasar tersebut nilai kemampuan lapisan tanah memikul beban setelah tanah dasar tersebaut dipadatkan. CBR ini disebut CBR laboratorium, karena disiapkan dilaboratorium. (Modul Praktek Mekanika Tanah 1, 2017)

\section{METODE PENELITIAN}

Metode yang digunakan adalah metode survey, yaitu suatu penyelidikan yang bersifat kritis untuk memperoleh keterangan atas suatu persoalan di dalam suatu daerah atau wilayah dengan mengambil contoh (sampel) dari populasi yang ada. Data yang digunakan dalam penelitiaan ini adalah data primer dan sekunder. Data primer di dapat dari survey lapangan, LHR dan bahan bahan uji laboratorium yaitu limbah gypsum dan tanah dasar. Data sekunder didapat dari beberapa instansi terkait yaitu Badan Pusat Statistik Kabupaten OKU Timur, Dinas PU Kabupaten OKU Timur, Dinas Perhubungan Kabupaten OKU Timur dan Kepustakaan yang terkait dengan masalah penelitian ini.

\section{PEMBAHASAN}

\section{Keadaan Kelas Ruas Jalan Bk1 Desa Tanjung Bulan Kabupaten Ogan Komering Ulu Timur}

Berdasarkan hasil survey di lapangan diketahui bahwa di ruas jalan Bk1 Desa Tanjung Bulan Kabupaten Ogan Komering Ulu Timur hampir di sepanjang jalan tersebut mengalami kerusakan, terdapat banyak jenis kerusakan pada ruas jalan ini yaitu berlubang dengan kondisi jejak roda, retak kulit buaya, amblas dan retak selip. Hasil survey diketahui bahwa panjang ruas jalan Desa Tanjung Bulan Belitang Bk1 Kabupaten Ogan Komering Ulu Timur memiliki jarak panjang $\pm 6 \mathrm{~km}$, jalan tersebut termasuk jalan kelas III C yang hanya dapat dilalui kendaraan bermotor termasuk muatan dengan ukuran lebar tidak melebihi 2.100 milimeter, Ukuran panjang tidak melebihi 9000 milimeter, dan muatan sumbu terberat yang di izinkan 8 ton.

\section{Volume Lalu Lintas}

Volume lalu lintas adalah jumlah kendaraan yang melalui ruas jalan dalam satuan tertentu. Untuk penelitian yang dilakukan di ruas jalan Bk1 Desa Tanjung bulan Kabupaten Ogan Komering Ulu Timur volume lalu lintasnya di hitung perhari selama 7 hari mulai dari tanggal 19 juni 2018 sampai dengan 25 juni 2018 sehingga dapat diketahui secara terperinci spesifikasi kendaraan yang melintasi ruas jalan tersebut dengan waktuwaktu kepadatan serta beban-beban yang di tanggung oleh konstruksi jalan tersebut. Dengan analisa dan mencatat volume lalu lintas pada ruas jalan tersebut dapat diketahui apakah volume lalu lintas yang melaluinya merupakan salah satu penyebab utama sehingga ruas jalan tersebut menjadi rusak yang secara langsung mengurangi kenyamanan pengendara dalam melakukan perjalanan.

Dengan analisa dan mencatat volume lalu lintas kendaraan yang melintasi ruas jalan tersebut dapat diketahui apakah volume lalu lintas jalan tersebut merupakan salah satu 
penyebab utama kerusakan pada ruas jalan Bk1 Desa Tanjung Bulan Kabupaten Ogan Komering Ulu Timur. Data survey volume lalu lintas yang berada pada ruas jalan Bk1 Desa Tanjung Bulan Kabupaten Ogan Komering Ulu Timur dapat dilihat pada tabel rekapitulasi volume lalu lintas berikut :

Tabel 1. Rekapitulasi Keseluruhan Data Lalu Lintas Harian Rata-Rata (LHR) dari Tanggal 19 Juni 2018 Sampai Dengan 25 Juni 2018

\begin{tabular}{|c|c|c|c|c|c|}
\hline Tanggal & $\begin{array}{l}\text { Sepeda } \\
\text { Motor }\end{array}$ & $\begin{array}{c}\text { Kendaraan } \\
\text { Pribadi }\end{array}$ & Pick-Up & Truk & $\begin{array}{c}\text { TOTAL } \\
\text { LHR }\end{array}$ \\
\hline 19 Juni 2018 & 368 & 191 & 67 & 79 & \multirow{7}{*}{$\begin{array}{c}\text { TOTAL } \\
\text { LHR }\end{array}$} \\
\hline 20 Juni 2018 & 340 & 165 & 91 & 66 & \\
\hline 21 Juni 2018 & 391 & 214 & 76 & 88 & \\
\hline 22 Juni 2018 & 316 & 181 & 83 & 65 & \\
\hline 23 Juni 2018 & 310 & & 86 & 93 & \\
\hline 24 Juni 2018 & 334 & 153 & 96 & 65 & \\
\hline 25 Juni 2018 & 394 & 162 & & 72 & \\
\hline Jumlah & & & 579 & 502 & 4823 \\
\hline
\end{tabular}

Sumber : Analisa Data

$L H R=\frac{4823}{7}=689$

Pada Tabel 1 terlihat bahwa rekapitulasi keseluruhan data lalu lintas harian rata-rata (LHR) dari tanggal 19 juni 2018 - 25 juni 2018 adalah sebanyak 689 kendaraan.

\section{Hasil CBR (California Bearing Ratio) dan DDT}

Pemeriksaan nilai CBR menggunakan CBR metode CBR laboratorium yaitu pemeriksaan langsung pada contoh tanah asli tanpa perendaman. Uji percobaan dilakukan di Laboratorium Fakultas Teknik Sipil Universitas Baturaja.

Tabel 2. Hasil nilai CBR tanah dasar sebelum dan sesudah dicampur Limbah Gypsum pada titik 1

\begin{tabular}{|l|l|c|}
\hline No & Tanah dasar + Semen $(\%)$ & Hasil Nilai CBR \\
\hline 1 & Tanah dasar & 0.74 \\
\hline
\end{tabular}




\begin{tabular}{|l|l|c|}
\hline 2 & Tanah dasar + Limbah Gypsum 5\% & 0,88 \\
\hline 3 & Tanah dasar + Limbah Gypsum 10\% & 1,18 \\
\hline 4 & Tanah dasar + Limbah Gypsum 15\% & 1,905 \\
\hline 5 & Tanah dasar + Limbah Gypsum 20\% & 1,525 \\
\hline
\end{tabular}

Sumber : Analisa Data

Tabel 3. Hasil nilai CBR tanah dasar sebelum dan sesudah Limbah Gypsum pada titik 2

\begin{tabular}{|l|l|c|}
\hline No & Tanah dasar + Semen $(\%)$ & Hasil Nilai CBR \\
\hline 1 & Tanah dasar & 1,07 \\
\hline 2 & Tanah dasar + Limbah Gypsum 5\% & 1,725 \\
\hline 3 & Tanah dasar + Limbah Gypsum 10\% & 3,305 \\
\hline 4 & Tanah dasar + Limbah Gypsum 15\% & 7,1 \\
\hline 5 & Tanah dasar + Limbah Gypsum 20\% & 5,27 \\
\hline
\end{tabular}

Sumber : Analisa Data

Tabel 4. Hasil nilai CBR tanah dasar sebelum dan sesudah dicampur Limbah Gypsum pada titik 3

\begin{tabular}{|l|l|c|}
\hline No & Tanah dasar + Semen $(\%)$ & Hasil Nilai CBR \\
\hline 1 & Tanah dasar & 0,91 \\
\hline 2 & Tanah dasar + Limbah Gypsum 5\% & 2,84 \\
\hline 3 & Tanah dasar + Limbah Gypsum 10\% & 3,595 \\
\hline 4 & Tanah dasar + Limbah Gypsum 15\% & 6,285 \\
\hline 5 & Tanah dasar + Limbah Gypsum 20\% & 4,98 \\
\hline
\end{tabular}

Sumber : Analisa Data

Tabel 5. Hasil nilai CBR tanah dasar sebelum dan sesudah dicampur Limbah Gypsum pada titik 4

\begin{tabular}{|l|l|c|}
\hline No & Tanah dasar + Semen $(\%)$ & Hasil Nilai CBR \\
\hline 1 & Tanah dasar & 0,85 \\
\hline 2 & Tanah dasar + Limbah Gypsum 5\% & 2,67 \\
\hline 3 & Tanah dasar + Limbah Gypsum 10\% & 3,08 \\
\hline
\end{tabular}




\begin{tabular}{|l|l|c|}
\hline 4 & Tanah dasar + Limbah Gypsum 15\% & 4,4 \\
\hline 5 & Tanah dasar + Limbah Gypsum 20\% & 3,845 \\
\hline
\end{tabular}

Sumber : Analisa Data

Tabel 6. Hasil nilai CBR tanah dasar sebelum dan sesudah dicampur Limbah Gypsum pada titik 5

\begin{tabular}{|l|l|c|}
\hline No & Tanah dasar + Semen $(\%)$ & Hasil Nilai CBR \\
\hline 1 & Tanah dasar & 1,15 \\
\hline 2 & Tanah dasar + Limbah Gypsum 5\% & 3,06 \\
\hline 3 & Tanah dasar + Limbah Gypsum 10\% & 5,27 \\
\hline 4 & Tanah dasar + Limbah Gypsum 15\% & 7,26 \\
\hline 5 & Tanah dasar + Limbah Gypsum 20\% & 6,045 \\
\hline
\end{tabular}

Sumber : Analisa Data Juni 2018

Tabel 7. Hasil nilai CBR tanah dasar sebelum dan sesudah dicampur Limbah Gypsum pada titik 6.

\begin{tabular}{|l|l|c|}
\hline No & Tanah dasar + Semen $(\%)$ & Hasil Nilai CBR \\
\hline 1 & Tanah dasar & 0,95 \\
\hline 2 & Tanah dasar + Limbah Gypsum 5\% & 3,29 \\
\hline 3 & Tanah dasar + Limbah Gypsum 10\% & 4,145 \\
\hline 4 & Tanah dasar + Limbah Gypsum 15\% & 7,16 \\
\hline 5 & Tanah dasar + Limbah Gypsum 20\% & 5,17 \\
\hline
\end{tabular}

Sumber : Analisa Data

Tabel 8. Peningkatan Hasil Keseluruhan Nilai CBR Tanah Dasar Terhadap Campuran Limbah Gypsum

\begin{tabular}{|c|l|c|c|c|c|c|c|}
\hline \multirow{2}{*}{ No } & \multirow{2}{*}{ Komposisi Campuran } & \multicolumn{7}{|c|}{ Titik Sample } \\
\cline { 4 - 9 } & & 1 & 2 & 3 & 4 & 5 & 6 \\
\hline 1 & Tanah dasar & 0,73 & 1,07 & 0,91 & 0,85 & 1,15 & 0,96 \\
\hline 2 & $\begin{array}{l}\text { Tanah dasar + Limbah } \\
\text { Gypsum 5\% }\end{array}$ & 0,88 & 1,725 & 2,84 & 2,67 & 3,06 & 3,29 \\
\hline
\end{tabular}




\begin{tabular}{|c|l|c|c|c|c|c|c|}
\hline 3 & $\begin{array}{l}\text { Tanah dasar + Limbah } \\
\text { Gypsum 10\% }\end{array}$ & 1,18 & 3,305 & 3,545 & 3,08 & 5,27 & 4,145 \\
\hline 4 & $\begin{array}{l}\text { Tanah dasar + Limbah } \\
\text { Gypsum 15\% }\end{array}$ & 1,905 & 7,1 & 6,285 & 4,4 & 7,26 & 7,16 \\
\hline 5 & $\begin{array}{l}\text { Tanah dasar + Limbah } \\
\text { Gypsum 20\% }\end{array}$ & 1,525 & 5,27 & 4,98 & 3,845 & 6,046 & 5,17 \\
\hline
\end{tabular}

Sumber : Analisa Data

Dari Tabel 6 terlihat bahwa nilai CBR tanah dasar dengan penambahan limbah gypsum mengalami kenaikan. Penambahan limbah gypsum pada tanah dasar menyebabkan kenaikan nilai CBR secara signifikan disetiap titiknya. Terlihat bahwa setiap penambahan campuran limbah gypsum dengan kadar 5\%, 10\%,dan 15\% terjadi kenaikan nilai CBR pada tanah dasar. Nilai CBR tertinggi yaitu 7,26 terdapat pada titik 5 dengan komposisi tanah dasar ditambah limbah gypsum sebesar 15\%. Adapun grafik peningkatan nilai CBR limbah gypsum setelah di stabilisasi dapat dilihat pada gambar 1 .

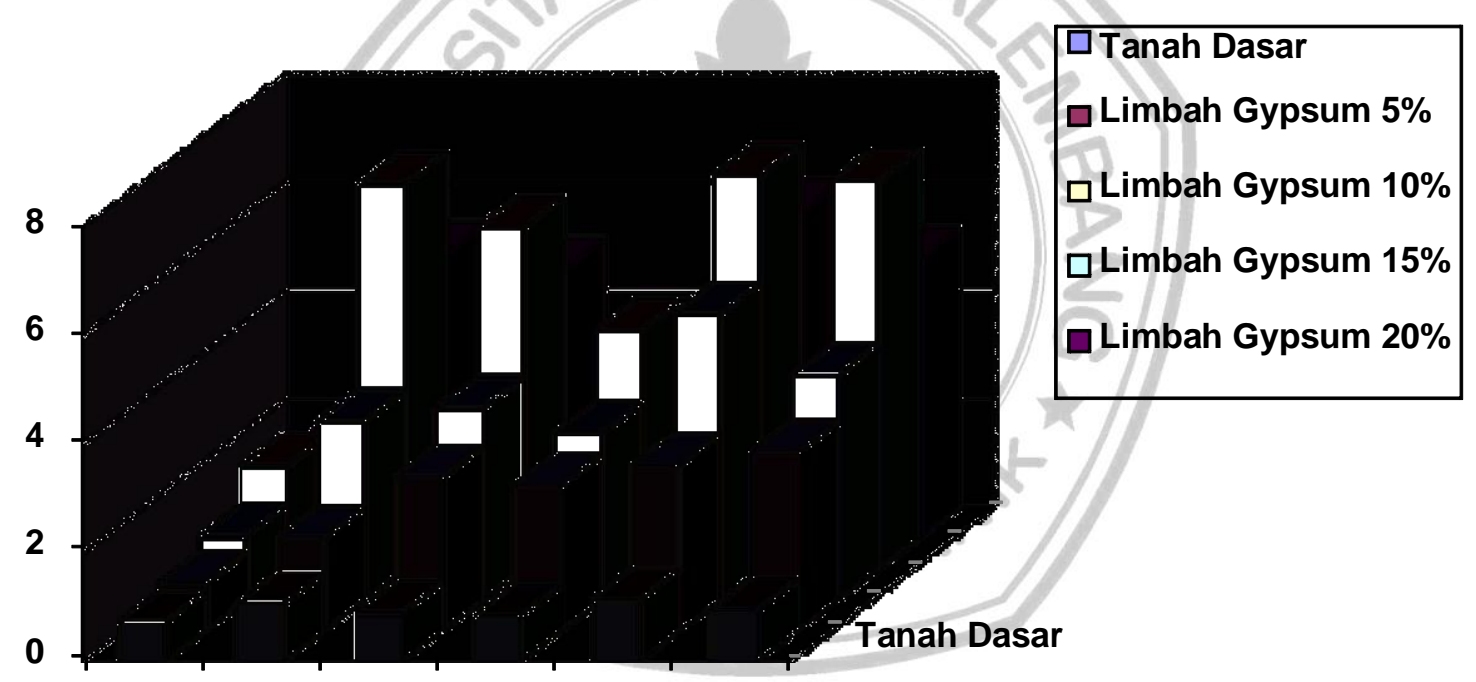

Titik 1 Titik 2 Titik 3 Titik 4 Titik 5 Titik 6

Gambar 1. Grafik Peningkatan Nilai CBR Limbah Gypsum Setelah di Stabilisasi.

\section{KESIMPULAN}

Berdasarkan penelitian lapangan pada ruas Jalan bk1 Desa Tanjung Bulan Kabupaten OKU Timur dan pada penelitian di Laboratorium Fakultas Teknik Sipil Universitas Baturaja maka dapat disimpulkan bahwa hasil penelitian pengaruh penambahan limbah gypsum terhadap nilai CBR pada tanah dasar mengalami peningkatan sebagai berikut :

a. Setiap penambahan campuran limbah gypsum dengan kadar 5\%, 10\%, dan $15 \%$ terjadi kenaikan nilai CBR pada tanah dasar. Kenaikan nilai terbesar yaitu $7.26 \mathrm{KN} / \mathrm{m} 2$, Pada 
titik 6 dan kadar limbah gypsum 15\%. Selanjutnya Pada kadar $20 \%$ terjadi penurunan.

b. Material limbah gypsum hanya efektif berfungsi pada campuran dengan kadar $15 \%$ untuk lokasi penelitian di ruas jalan bk 1 jalan tanjung bulan.

c. Semakin besar kadar limbah gypsum yang ditambahkan, maka daya dukung tanah akan mengalami penurunan di karenakan gypsum terlalu banyak menyerap air.

\section{DAFTAR PUSTAKA}

Modul Praktek Mekanika Tanah I. 2017. Jurusan Teknik Sipil Universitas Baturaja

Suryono, S, Kazuto,N. 1980. Mekanika Tanah dan Teknik Pondasi. Jakarta.

Sanglerat G, Olivari, G, Combou, B. 1987. Soal - soal Praktis Dalam Mekanika Tanah dan Teknik Pondasi. Jakarta.

Santoso, B, Suprapto H, Suryadi, HS. 2011. Diktat Kuliah Dasar Mekanika Tanah. Gunadarma Jakarta

Ibnu,S. 2006, Studi Eksperimen Pengaruh Pencampuran Serbuk Batu Bara dan Serbuk Gipsum terhadap Kuat Dukung Tanah Lempung dengan Metode Meyerhof. Jurnal terpublikasi. Jogjakarta: Universitas Islam Indonesia Jogjakarta.

Vemmy, dkk, 2013, Pengaruh Penambahan Serbuk Gypsum Dengan Lamanya Waktu Pengeraman (curing) TerhadapKarakteristik Tanah Lempung Ekspansif di Bojonegoro, Jurnal Penelitian, Universitas Brawijaya Malang, Malang. 